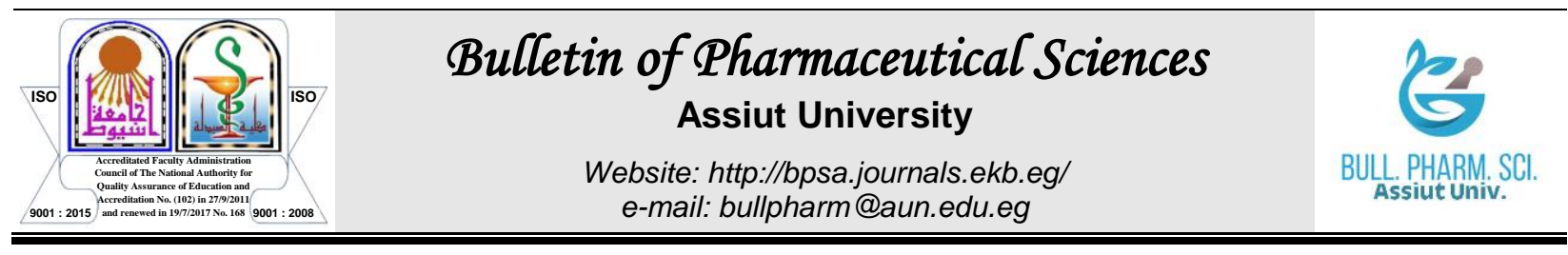

\title{
EFFECT OF INTRAOPERATIVE DEXMEDETOMIDINE ON RENAL FUNCTION IN PATIENTS UNDERGOING CARDIOPULMONARY BYPASS GRAFT SURGERY UNDER CARDIOPULMONARY BYPASS
}

\author{
Mansour Jannati ${ }^{1 *}$, Shahrbanoo Shahbazi ${ }^{2}$ and Hamid Reza Lotfi ${ }^{3}$ \\ ${ }^{1}$ Cardiovascular Surgery Ward, Namazee Hospital, Shiraz University of Medical Sciences, \\ Shiraz, Iran \\ ${ }^{2}$ Department of Anaesthesiology, Shiraz University of Medical Sciences, Shiraz, Iran \\ ${ }^{3}$ Master student, Shiraz University of Medical Sciences, Shiraz, Iran
}

\begin{abstract}
Acute kidney injury (AKI) post-cardiac surgeries happens as a prompt deterioration in renal function subsequent to cardiac surgery including cardiopulmonary bypass graft surgery $(C A B G)$. This study is aimed to evaluate the effect of intraoperative dexmedetomidine on renal function in patients undergoing $C A B G$ by using cardiopulmonary bypass (CPB). Methods. This Double-blinded randomized clinical trial study was performed on 58 patients who were candidates for CABG in Namazi Hospital of Shiraz. In the dexmedetomidine group, dexmedetomidine infusion at a dose of $0.5 \mu \mathrm{g} / \mathrm{kg} / \mathrm{h}$ without a loading dose, and in the control group placebo was initiated. After the end of surgery and ICU admission and on days 2 and 3 postoperatively, serum BUN, $\mathrm{Cr}$, and eGFR levels, also urine output, Inotrope usage, and packed red blood cells (PRBC) consumption were recorded. SPSS software 24 was used for data analysis. Results. No significant differences were observed in any of the steps in serum creatinine levels between the two groups $(P>0.05)$. A significant difference in serum BUN levels was observed between the two groups except for the third day $(P<0.05)$. Heterogeneity was seen in preoperative BUN in the two groups. There was no significant difference between the mean of eGFR in the dexmedetomidine and control groups over time $(P>0.05)$. There was a significant difference between the mean urine output in the two groups only on the second day $(P=0.04)$. There was no significant difference in PRBC intake and inotrope usage between the two groups $(P>0.05)$. Conclusion. The findings of this study indicate that dexmedetomidine does not affect the renal function of patients undergoing coronary artery bypass graft surgery. According to the findings, dexmedetomidine can increase the urine output of patients during surgery. However, it has no positive effect on the postoperative period.
\end{abstract}

\section{INTRODUCTION}

Acute kidney injury (AKI) post-cardiac surgeries happen as a prompt deterioration in renal function subsequent to cardiac surgery. It is determined as a considerable reduction in the glomerular filtration rate (GFR). The incidence of cardiac surgery-associated acute kidney injury (CSA-AKI) is about $30 \%$ and is related to an increase in mortality and morbidity ${ }^{1}$. The mechanisms such as neurohormonal activation, microembolization, hemodynamic factors, exogenous and endogenous toxins, metabolic factors, ischemia-reperfusion injury, inflammation factors, and oxidative stress may involve in the pathophysiology of $\mathrm{AKI}^{2}$. The use of cardio-pulmonary bypass (CPB) has been related to changes in vasomotor tone and decreases the renal parenchymal oxygen tension, and increases the ischemia-reperfusion $(\mathrm{I} / \mathrm{R})$ injury. Besides, CPB activates the systemic inflammatory response and produces microemboli ${ }^{3}$. Cardiac surgery stimulates the sympathetic nervous system and resulted in releasing of epinephrine and norepinephrine and makes hemodynamics unstable, that detriment the renal function ${ }^{4}$. The AKI postcardiac surgery may lead to chronic kidney 
disease, enhances mortality, decreases the quality of life, and increases the risks of cardiovascular event ${ }^{5}$.

Dexmedetomidine, an alpha2-adrenergic agonist, has been revealed to decrease anesthetic requirements, increase the stability of hemodynamic, provide sedation, induces anti-inflammation, and diuresis while using preoperative in cardiac surgery ${ }^{6-9}$. In a study, it is reported that dexmedetomidine could efficiently eliminate the increase of cocaineinduced sympathetic activation and vasoconstriction ${ }^{10}$. In laboratory studies, it has been demonstrated that dexmedetomidine can protect renal function via sympathetic system stabilization, anti-inflammatory effects, and weakening I/R injury ${ }^{11-12}$. Several studies with a somewhat small sample size have evaluated the effect of dexmedetomidine on AKI after cardiac surgeries, however, the results are controversial $^{13-15}$. Whether intraoperative use of dexmedetomidine in patients undergoing cardiac surgery could decrease the risk for AKI in these patients remains uncertain. Therefore, this study is aimed to evaluate the effect of intraoperative dexmedetomidine on renal function in patients undergoing $\mathrm{CABG}$ by using CPB.

\section{MATERIALS AND METHODS}

This Double-blinded randomized clinical trial study was performed on 58 patients younger than 70 years with coronary artery disease who were candidates for CABG surgery in Namazi Hospital. Patients are randomly assigned into two groups of intervention and control using the randomized table which is drives from randomozation.org. The inclusion criteria were people under the age of 70 who were candidates for CABG surgery and were operated by the same cardiac surgeon with the same technique using the on pump method and under cardiac arrest. The exclusion criteria were emergency surgery, redo surgery, $\mathrm{CABG}$ surgery along with other cardiac surgeries, preoperative kidney problems $(\mathrm{Cr}>1.4)$, use of total circulatory arrest (TCA) during bypass, having systolic heart failure $(\mathrm{EF}<40)$, requires intra-aortic balloon pump (IABP) postoperatively.

The study is performed as follows after approval of the Research Ethics Committee of
Shiraz University of Medical Sciences and registration in the National Committee for Ethics in Biomedical Research under the registration number IR.SUMS.REC.1398.015 and the Clinical Trial Registration System of Iran under the registration number IRCT20141009019470N83 and obtaining written informed consent from patients.

Patients were admitted to the operating room and their height and weight were calculated. In the Supine position ' they were initially monitored by ECG, arterial oxygen saturation (SPO2), and non-invasive blood pressure (NIBP). Then two venous lines and one arterial line were inserted. After routine anesthetic injection (a combination of midazolam, sufentanil, pancuronium bromide, thiopental sodium), the patients were orally intubated and mechanically ventilated. Then, from the internal jugular area، a Central venous line was obtained and they were monitored for invasive blood pressure (IBP), central venous pressure (CVP), temperature (T), and end-tidal carbon dioxide (ETCO2). After induction of anesthesia in the dexmedetomidine group, dexmedetomidine infusion at a dose of 0.5 $\mu \mathrm{g} / \mathrm{kg} / \mathrm{h}$ without a loading dose and in the control group placebo (normal saline) was initiated by the anesthesiologist, who was not involved in the later stages of the study and continued until the end of the operation. Dexmedetomidine and placebo were also prepared by another anesthesiologist who was not involved in the later stages of the study. Patients' demographic data including age, sex, height, weight, BUN, $\mathrm{Cr}, \mathrm{Hb}, \mathrm{HCT}$, and preoperative HCT were recorded in a questionnaire. After induction of anesthesia heart rate (HR) and mean arterial pressure was recorded every 15 minutes until the start of $\mathrm{CPB}$ and after the end of CPB. After CPB initiation, MAP was maintained between 50-80 $\mathrm{mmHg}$, and the duration of $\mathrm{CPB}$ and aortic clamp, urine output, hemofiltration, and transfused PRBC volume were recorded in the questionnaire. Cardioplegia composition for all samples was identical and it was DELNIDO Modified (sodium bicarbonate $25 \mathrm{mEq} / \mathrm{l}$ potassium chloride $30 \mathrm{mEq} / \mathrm{l}$, magnesium sulfate $2.5 \mathrm{~g} / \mathrm{l}$, lidocaine $100 \mathrm{mg} / \mathrm{l}$ in normal saline $4^{\circ} \mathrm{C}$ ) and was injected into the aortic root by the antegrade method. All patients were treated with mild hypothermia (33-35 degrees 
Celsius) during $\mathrm{CPB}$ and warmed to 37 degrees Celsius after distal grafts endings. After the end of surgery and ICU admission as well as on days 2 and 3 postoperatively, serum BUN, Cr, and eGFR levels were recorded in the questionnaire. The amount of consumed blood and urinary output were also recorded in the ICU. Besides, the use of nephrotoxic and diuretic drugs was recorded, in which nephrotoxic drugs were not used in any of the patients and all patients were routinely given $20 \mathrm{mg}$ Furosemide tablets every 12 hours after the second day of operation.

The Cockroft-gault formula was used to calculate eGFR (estimated glomerular filtration rate). It is based on calculated creatinine clearance and is calculated based on patients' gender, weight, age, and serum creatinine.

Six patients (4 in the Dexmedetomidine group and 2 in the control group) were excluded due to the use of a post-operative intra-aortic balloon pump.

\section{Statistical analysis}

SPSS software 24 was used for data analysis .First, the results of homogeneity of variables of age, sex, height, weight, preoperative hematocrit, preoperative hemoglobin, ejection fraction, mean arterial pressure, duration of mechanical ventilation in ICU, amount of intraoperative blood received, number of grafts, Bypass time, aortic crossclamp time, and hemofiltration rate in the dexmedetomidine and control groups were demonstrated using chi-square, independent $t$ test, Fisher exact test, and Mann-Whitney test.

Then, since the aim of this study was to investigate the effect of intraoperative dexmedetomidine on renal function of patients undergoing coronary artery bypass graft and cardiopulmonary bypass surgery and the renal function of patients was measured at different stages, the repeated-measures ANOVA was used. It should be noted that the KolmogorovSmirnov test was used to check the normality of the variables.

\section{RESULTS AND DISCUSSION}

\section{Results}

Table 1: Shows the demographic features of patients in dexmedetomidine and control groups before surgery.

There was no significant difference in terms of sex $(P=0.29)$. There was a significant difference between the mean age of the two groups $(\mathrm{P}=0.03)$. Therefore, the two groups were not homogeneous in terms of age.

There was no significant difference between mean preoperative hematocrit, preoperative hemoglobin, ejection fraction, duration of mechanical ventilation in ICU, and mean arterial pressure in both Dexmedetomidine and control groups $(\mathrm{P}<$ $0.05)$.

Table 1: Demographic features of patients in Dexmedetomidine and control groups

\begin{tabular}{|l|l|l|l|}
\hline & Dexmedetomidine & Control & P-value \\
\hline Sex & & & 0.29 \\
\hline Male & $12(42.9)$ & $17(56.7)$ & \\
\hline Female & $16(57.1)$ & $13(43.3)$ & \\
\hline Age, y & $60.82 \pm 6.47$ & $57.7 \pm 6.57$ & 0.03 \\
\hline Preoperative Hematocrit, \% & $38.28 \pm 4.52$ & $40.57 \pm 4.57$ & 0.06 \\
\hline Preoperative Hemoglobin, g/dl & $12.87 \pm 1.78$ & $13.72 \pm 1.84$ & 0.08 \\
\hline Ejection Fraction & $51.07 \pm 7.25$ & $50.83 \pm 8.1$ & 0.91 \\
\hline Mean arterial pressure, mmHg & $65.80 \pm 4.21$ & $67.47 \pm 3.23$ & 0.09 \\
\hline Duration of mechanical ventilation in ICU & $14.46 \pm 5.74$ & $18.26 \pm 10.67$ & 0.31 \\
\hline Number of Grafts & $3.39 \pm 0.63$ & $3.46 \pm 0.68$ & 0.67 \\
\hline Bypass time, min & $76.86 \pm 86$ & $85.40 \pm 20.14$ & 0.1 \\
\hline Aortic cross-clamp time, min & $40.75 \pm 8.83$ & $47.40 \pm 12.09$ & 0.02 \\
\hline Hemofiltration & $2017.86 \pm 452.19$ & $2683.86 \pm 977.71$ & 0.01 \\
\hline Phosphorylcholine (PC)-coated CPB & $0.77 \pm 0.14$ & $0.85 \pm 0.15$ & 0.52 \\
\hline Urine volume during bypass, ml & $692.86 \pm 405.91$ & $471.67 \pm 327.13$ & 0.02 \\
\hline
\end{tabular}

Data are presented as No. (\%) and mean \pm SD. 
There was a significant difference between the mean variables of aortic crossclamp time, urine volume during bypass, and hemofiltration in the Dexmedetomidine and control groups $(\mathrm{P}<0.05)$.

According to Table 2, no significant differences were observed in any of the steps in serum $\mathrm{Cr}$ levels between the two groups $(\mathrm{P}<$ $0.05)$. Since, the study aimed to compare the mean serum $\mathrm{Cr}$ level over time in each of the Dexmedetomidine and control groups, repeated measures ANOVA test was used. Results showed that the mean creatinine in the Dexmedetomidine group $(\mathrm{P}=0.007, \mathrm{~F}=5.48)$ and in the control group $(\mathrm{P}=0.018, \mathrm{~F}=4.3)$ was significantly different over time.

Table 2: Shows a significant difference in serum BUN levels between the two groups except for the third day $(\mathrm{P}<0.05)$. Since, the study aimed to compare the mean serum BUN level in each of the Dexmedetomidine and control groups over time, repeated measures ANOVA test was used. Results showed that the mean BUN in the Dexmedetomidine group $(\mathrm{F}=$ 7.76, $\mathrm{P}<0.001)$ and in the control group $(\mathrm{F}=$ $37.39, \mathrm{P}<0.001)$ were significantly different over time.

According to Table 2, there was a significant difference between the mean of eGFR in the Dexmedetomidine and control groups just before the intervention $(\mathrm{p}=0.03)$. Since, the study aimed to compare the mean of eGFR in each of the Dexmedetomidine and control groups over time, repeated measures ANOVA test was used. The results showed that the mean of eGFR in the Dexmedetomidine group $(\mathrm{F}=11.98, \mathrm{P}<0.001)$ and in the control group $(\mathrm{F}=7.14, \mathrm{P}<0.001)$ was significantly different over time.

Table 2: The mean and standard deviation of serum level of Cr, BUN, and eGFR in Dexmedetomidine and control group preoperative, $1^{\text {st }}, 2^{\text {nd }}$, and $3^{\text {rd }}$ days after surgery and mean differences of them between $1^{\text {st }}, 2^{\text {nd }}$, and $3^{\text {rd }}$ days and preoperative

\begin{tabular}{|c|c|c|c|c|c|c|c|c|c|}
\hline \multirow{2}{*}{ Days } & \multicolumn{3}{|l|}{$\mathrm{Cr}$} & \multicolumn{3}{|l|}{ BUN } & \multicolumn{3}{|l|}{ eGFR } \\
\hline & Dexmedetomidine & Control & t-test & Dexmedetomidine & Control & t-test & Dexmedetomidine & Control & t-test \\
\hline Preoperative & $0.95 \pm 0.15$ & $0.99 \pm 0.19$ & $\begin{array}{l}\mathrm{t}=-0.87 \\
\mathrm{P}=0.38\end{array}$ & $18.75 \pm 5.25$ & $16.13 \pm 3.45$ & $\begin{array}{l}\mathrm{t}=2.22 \\
\mathrm{P}=0.03\end{array}$ & $82.78 \pm 19.8$ & $71.66 \pm 1762$ & $\begin{array}{l}\mathrm{t}=2.26 \\
\mathrm{P}=0.03\end{array}$ \\
\hline $1 \mathrm{st}$ & $1.04 \pm 0.14$ & $1.07 \pm 0.26$ & $\begin{array}{l}t=-0.54 \\
P=0.58\end{array}$ & $20.36 \pm 6.54$ & $14.97 \pm 3.61$ & $\begin{array}{l}t=3.84 \\
P<0.001\end{array}$ & $75.68 \pm 20.08$ & $68.04 \pm 20.43$ & $\begin{array}{l}\mathrm{t}=1.43 \\
\mathrm{P}=0.16\end{array}$ \\
\hline 2nd & $1.18 \pm 0.21$ & $1.24 \pm 0.41$ & $\begin{array}{l}t=-0.07 \\
P=0.47\end{array}$ & $24.07 \pm 10.37$ & $19.53 \pm 5.19$ & $\begin{array}{l}\mathrm{t}=2.08 \\
\mathrm{P}=0.04\end{array}$ & $67.08 \pm 19.69$ & $59.59 \pm 17.1$ & $\begin{array}{l}t=1.69 \\
P=0.09\end{array}$ \\
\hline $3 r d$ & $1.17 \pm 0.29$ & $1.15 \pm 0.36$ & $\begin{array}{l}t=0.24 \\
P=0.8\end{array}$ & $26.07 \pm 11.36$ & $25.03 \pm 8.27$ & $\begin{array}{l}\mathrm{t}=0.39 \\
\mathrm{P}=0.69\end{array}$ & $69.4 \pm 20.67$ & $25.03 \pm 8.27$ & $\begin{array}{l}\mathrm{t}=1.12 \\
\mathrm{P}=0.27\end{array}$ \\
\hline $\begin{array}{l}\text { Difference } \\
\text { between 1st } \\
\text { day and } \\
\text { preoperative }\end{array}$ & $0.093 \pm 1.46$ & $0.83 \pm 1.84$ & $\begin{array}{l}\mathrm{t}=0.22 \\
\mathrm{P}=0.83\end{array}$ & $1.61 \pm 5.89$ & $-1.16 \pm 3.76$ & $\begin{array}{l}t=2.12 \\
P=0.04\end{array}$ & $-7.1 \pm 10.88$ & $-3.62 \pm 13.37$ & $\begin{array}{l}t=1.08 \\
P=0.28\end{array}$ \\
\hline $\begin{array}{l}\text { Difference } \\
\text { between 2nd } \\
\text { day and } \\
\text { preoperative }\end{array}$ & $0.23 \pm 0.25$ & $0.25 \pm 0.31$ & $\begin{array}{l}t=-0.28 \\
P=0.77\end{array}$ & $5.32 \pm 9.35$ & $3.4 \pm 5.11$ & $\begin{array}{l}t=-0.65 \\
P=0.51\end{array}$ & $-14.98 \pm 17.02$ & $-12.07 \pm 16.79$ & $\begin{array}{l}t=-0.65 \\
P=0.51\end{array}$ \\
\hline $\begin{array}{l}\text { Difference } \\
\text { between 3rd } \\
\text { day and } \\
\text { preoperative }\end{array}$ & $0.22 \pm 0.31$ & $0.16 \pm 0.25$ & $\begin{array}{l}F=5.48 \\
P=0.007\end{array}$ & $7.32 \pm 9.72$ & $8.9 \pm 7.62$ & $\begin{array}{l}\mathrm{t}=-069 \\
\mathrm{p}=0.49\end{array}$ & $-13.38 \pm 19.08$ & $-7.78 \pm 12.81$ & $\begin{array}{l}t=-1.32 \\
P=0.19\end{array}$ \\
\hline $\begin{array}{l}\text { Result of } \\
\text { repeated } \\
\text { measure } \\
\text { ANOVA }\end{array}$ & $\begin{array}{l}F=5.48 \\
P=0.007\end{array}$ & $\begin{array}{l}F=4.3 \\
P=0.018\end{array}$ & & $\begin{array}{l}F=7.76 \\
P<0.001\end{array}$ & $\begin{array}{l}F=37.39 \\
P<0.001\end{array}$ & & $\begin{array}{l}F=11.98 \\
P<0.001\end{array}$ & $\begin{array}{l}F=7.14 \\
P<0.001\end{array}$ & \\
\hline
\end{tabular}

According to Table 3, there was a significant difference between the mean urine output in the two groups only on the second day $(\mathrm{p}=0.04)$. 
Since, the study aimed to compare the mean urinary output in each of the Dexmedetomidine and control groups over time, repeated measures ANOVA tests were used. The results showed that the mean urinary output was significantly different in the Dexmedetomidine $(\mathrm{P}<0.001, \mathrm{~F}=48.46)$ and in the control groups $(\mathrm{F}=9.80, \mathrm{P}<0.001)$.

There was no significant difference between the mean of inotrope usage (VIS) in the two Dexmedetomidine and control groups $(\mathrm{p}<0.05)$ (Table 3).

Results of repeated measures ANOVA showed that the mean inotrope usage was significantly different in the Dexmedetomidine $(\mathrm{P}=0.001, \mathrm{~F}=29.03)$ and the control groups $(\mathrm{P}=0.001, \mathrm{~F}=11.24)$ over time.

The results of repeated measures ANOVA showed that the mean urine output in the Dexmedetomidine $(\mathrm{P}=0.001, \mathrm{~F}=7.52)$ and in the control groups $(\mathrm{P}=0.008, \mathrm{~F}=4.57)$ was significantly different over time (Table 4).

According to Table 4, there was no significant difference between the mean of inotrope usage in the two Dexmedetomidine and control groups $(\mathrm{p}<0.05)$.

The results of the repeated measures ANOVA test showed that the mean usage of Inotrope was significantly different only in the Dexmedetomidine group $(\mathrm{P}=0.004, \mathrm{~F}=7.42)$ over time.

\section{Discussion}

AKI usually happens post-cardiac surgery under $\mathrm{CPB}$, which leads to $60 \%$ of deaths in patients undergoing cardiac surgery ${ }^{16}$. The early diagnosis and intervention of AKI in patients subjected to cardiac surgery under $\mathrm{CPB}$ are essential. Hemodynamic and inflammatory factors and $\mathrm{I} / \mathrm{R}$ injury are involving in the development of $\mathrm{AKI}^{17}$. Dexmedetomidine, has an anti-inflammatory effect, stabilizing hemodynamic and inhibit the central sympathetic outflow ${ }^{4}{ }^{18}$. In this paper, we analyzed the effect of intraoperative dexmedetomidine on patients with CABG under CPB.

Table 3: The mean and standard deviation of serum level of urinary output and Inotrope Usage in Dexmedetomidine and control group preoperative, $1^{\text {st }}, 2^{\text {nd }}$, and $3^{\text {rd }}$ days after surgery and mean differences of them between $1^{\text {st }}, 2^{\text {nd }}$, and $3^{\text {rd }}$ days and preoperative

\begin{tabular}{|c|c|c|c|c|c|c|}
\hline \multirow{2}{*}{ Days } & \multicolumn{3}{|c|}{ Urinary Output } & \multicolumn{3}{|c|}{ Inotrope Usage } \\
\hline & Dexmedetomidine & Control & t-test & Dexmedetomidine & Control & t-test \\
\hline $1^{\mathrm{st}}$ & $151.78 \pm 43.4$ & $150.95 \pm 48.53$ & $\begin{array}{l}\mathrm{t}=0.07 \\
\mathrm{P}=0.94\end{array}$ & $2.96 \pm 2.7$ & $3.06 \pm 3.73$ & $\begin{array}{l}\mathrm{t}=-0.11 \\
\mathrm{P}=0.91\end{array}$ \\
\hline $2^{\text {nd }}$ & $77.05 \pm 16.06$ & $90.45 \pm 29.96$ & $\begin{array}{l}\mathrm{t}=-2.14 \\
\mathrm{P}=0.04\end{array}$ & $0.59 \pm-.69$ & $0.99 \pm 1.54$ & $\begin{array}{l}t=-1.26 \\
P=021\end{array}$ \\
\hline $3^{\text {rd }}$ & $87.23 \pm 27.29$ & $77.46 \pm 35.96$ & $\begin{array}{l}\mathrm{t}=1.16 \\
\mathrm{P}=0.25\end{array}$ & $0.27 \pm 0.87$ & $0.61 \pm 1.73$ & $\begin{array}{l}\mathrm{t}=-0.93 \\
\mathrm{P}=0.35\end{array}$ \\
\hline $\begin{array}{c}\text { Difference } \\
\text { between } \\
\text { 2nd and 1st } \\
\text { day }\end{array}$ & $-74.73 \pm 47.13$ & $-60.49 \pm 53.68$ & $\begin{array}{l}\mathrm{t}=-1.07 \\
\mathrm{P}=0.29\end{array}$ & $-2.36 \pm 2.36$ & $-2.06 \pm 3.49$ & $\begin{array}{c}t=-0.38 \\
P=0.7\end{array}$ \\
\hline $\begin{array}{c}\text { Difference } \\
\text { between } \\
\text { 3rd and } 1 \text { st } \\
\text { day }\end{array}$ & $-64.55 \pm 50.47$ & $-73.49 \pm 65.54$ & $\begin{array}{l}t=-0.58 \\
P=0.56\end{array}$ & $-2.68 \pm 2.48$ & $-2.44 \pm 3.71$ & $\begin{array}{l}t=-0.29 \\
P=0.77\end{array}$ \\
\hline $\begin{array}{c}\text { Result of } \\
\text { repeated } \\
\text { measure } \\
\text { ANOVA }\end{array}$ & $\begin{array}{l}F=48.46 \\
P<0.001\end{array}$ & $\begin{array}{l}\mathrm{F}=29.8 \\
\mathrm{P}<0.001\end{array}$ & & $\begin{array}{l}F=29.03 \\
P<0.001\end{array}$ & $\begin{array}{l}F=11.24 \\
P=0.001\end{array}$ & \\
\hline
\end{tabular}

There was no significant difference between the mean of urine output in the two groups in any hours of the first day $(\mathrm{p}<0.05)$. 
According to the results of the effect of intraoperative dexmedetomidine on serum $\mathrm{Cr}$ level, in both groups, there was a gradual increase in $\mathrm{Cr}$ level in the first and second postoperative days compared to preoperative level and then in the third day, a decrease was observed in serum Cr levels. But there was no significant difference between the two groups in the mean serum $\mathrm{Cr}$ levels at a constant time (P> 0.05). In Zhai et al. study the level of $\mathrm{Cr}$ was increased significantly on the $3^{\text {rd }}$ day after surgery but the level of $\mathrm{Cr}$ was significantly lower in the dexmedetomidine group than in the placebo group ${ }^{14}$. In Leino et al. study, the perioperative creatinine clearance increased in both groups during the study $\left(0,1^{\text {st }}, 2^{\text {nd }}\right.$ days), with a significant time effect but without significant difference between the groups ${ }^{18}$.

According to the results regarding the effect of dexmedetomidine on intraoperative serum BUN level, we found that BUN in the Dexmedetomidine group at a preoperative time $(\mathrm{p}=0.03)$, the first day after surgery $(\mathrm{P}<0.001)$, and second day postoperatively $(\mathrm{p}=0.04)$ was significantly higher but on day 3 postoperatively, mean BUN was not significantly different between the two groups (P> 0.05). In Zhai et al. study the level of BUN was increased significantly on the $3^{\text {rd }}$ day after surgery but the level of BUN was significantly lower in the dexmedetomidine group than in the placebo group ${ }^{14}$. Because of the heterogeneity of preoperative BUN in the two groups, more complete studies are needed to conclude.

According to the results of the effect of intraoperative dexmedetomidine on eGFR levels in two groups, we observed a continuous decrease in eGFR in the first and second postoperative days compared to preoperative. But on the third postoperative day, there was a slight increase in eGFR compared to the second postoperative day, which may indicate a possible improvement in renal function and return to preoperative levels.

Table 4: The mean and standard deviation of serum level of urinary output and Inotrope Usage in Dexmedetomidine and control group in hours $0,1,2$, and 3 of the first day of admission in ICU

\begin{tabular}{|c|c|c|c|c|c|c|}
\hline \multirow[b]{2}{*}{ Hour } & \multicolumn{3}{|c|}{ Urinary Output } & \multicolumn{3}{|c|}{ Inotrope Usage } \\
\hline & Dexmedetomidine & Control & t-test & $\begin{array}{l}\text { Dexmedetomidin } \\
\text { e }\end{array}$ & Control & t-test \\
\hline 0 & $186.07 \pm 101.92$ & $\begin{array}{ll}200.67 & \pm \\
127.25 & \end{array}$ & $\begin{array}{l}t=-0.48 \\
P=0.63\end{array}$ & $4.96 \pm 6.07$ & $4.10 \pm 5.41$ & $\begin{array}{l}\mathrm{t}=-0.57 \\
\mathrm{P}=0.56\end{array}$ \\
\hline 1 & $231.43 \pm 78.44$ & $211.67 \pm 96.21$ & $\begin{array}{l}\mathrm{t}=0.85 \\
\mathrm{P}=0.39\end{array}$ & $3.96 \pm 4.95$ & $3.37 \pm 5.25$ & $\begin{array}{l}\mathrm{t}=-0.44 \\
\mathrm{P}=0.66\end{array}$ \\
\hline 2 & $189.29 \pm 71.75$ & $177 \pm 107.87$ & $\begin{array}{l}\mathrm{t}=0.51 \\
\mathrm{P}=0.61\end{array}$ & $2.96 \pm 3.34$ & $3.10 \pm 4.79$ & $\begin{array}{l}\mathrm{t}=-0.12 \\
\mathrm{P}=0.9\end{array}$ \\
\hline 3 & $156.79 \pm 60.55$ & $145.67 \pm 74.45$ & $\begin{array}{l}t=0.62 \\
P=0.54\end{array}$ & $2.32 \pm 2.54$ & $3.13 \pm 5.07$ & $\begin{array}{l}\mathrm{t}=-0.78 \\
\mathrm{P}=0.44\end{array}$ \\
\hline $\begin{array}{l}\text { Difference } \\
\text { between } 1 \text { and } \\
0 \text { hour }\end{array}$ & $45.36 \pm 91.06$ & $11.00 \pm 104.63$ & $\begin{array}{l}\mathrm{t}=1.33 \\
\mathrm{P}=0.19\end{array}$ & $-1.00 \pm 2.45$ & $-0.73 \pm 2.30$ & $\begin{array}{l}t=-0.43 \\
P=0.67\end{array}$ \\
\hline $\begin{array}{l}\text { Difference } \\
\text { between } 2 \text { and } \\
0 \text { hour }\end{array}$ & $3.21 \pm 114.05$ & $-23.66 \pm 125.41$ & $\begin{array}{l}\mathrm{t}=0.85 \\
\mathrm{P}=0.39\end{array}$ & $-2.00 \pm 3.54$ & $-1.00 \pm 3.50$ & $\begin{array}{l}\mathrm{t}=-1.08 \\
\mathrm{P}=0.28\end{array}$ \\
\hline $\begin{array}{l}\text { Difference } \\
\text { between } 3 \text { and } \\
0 \text { hour }\end{array}$ & $-29.28 \pm 87.89$ & $-55.00 \pm 122.27$ & $\begin{array}{l}\mathrm{t}=0.91 \\
\mathrm{P}=0.36\end{array}$ & $-2.64 \pm 4.51$ & $-0.96 \pm 3.83$ & $\begin{array}{l}\mathrm{t}=-1.53 \\
\mathrm{P}=0.13\end{array}$ \\
\hline $\begin{array}{l}\text { Result of } \\
\text { repeated } \\
\text { measure } \\
\text { ANOVA }\end{array}$ & $\begin{array}{l}F=7.52 \\
P=0.001\end{array}$ & $\begin{array}{l}F=4.57 \\
P=0.008\end{array}$ & & $\begin{array}{l}\mathrm{F}=7.42 \\
\mathrm{P}=0.004\end{array}$ & $\begin{array}{l}F=1.67 \\
P=0.2\end{array}$ & \\
\hline
\end{tabular}

The mean PRBC intake was $2.25 \pm 1.6$ in the Dexmedetomidine group and $2.26 \pm 1.6$ in the control group. Mann-Whitney test was used to compare the means in the two groups and there was no significant difference between the two groups $(\mathrm{p}=0.95, \mathrm{z}=-0.06)$. 
Comparing the eGFR between the two groups at constant time, it was found that the mean preoperative eGFR was higher in the Dexmedetomidine group than the control group, which was significant $(\mathrm{P}=0.03)$. Changes in eGFR were similar in both groups and no significant difference was observed between the two groups $(\mathrm{P}>0.05)$. In Yi Jo et al. study, eGFR was significantly lower in the control group than in the dexmedetomidine group at $5 \mathrm{~min}$ after $\mathrm{CPB}$ and 2 hours after $\mathrm{CPB}$, but eGFR changes over time showed no significant difference between 2 groups. Compared to the value at the preoperative time, eGFR decreased significantly at 5 min after $\mathrm{CPB}$ and 2 hours after $\mathrm{CPB}$ and 1 day after surgery in the control group and at 5 min after CPB and 2 hours after CPB in the dexmedetomidine group ${ }^{19}$.

According to the results regarding the effect of dexmedetomidine on intraoperative urine output in the two groups, the mean of urinary output on the second day was lower than the control group $(p=0.04)$. There was no significant difference in mean urine output between the two groups on the first and third days after surgery. There was no significant difference between the urinary outputs in the two groups in the first three hours of admission in the intensive care unit. Besides, there was a significant difference between the two groups in the rate of intraoperative urine output, which was significantly higher in the Dexmedetomidine group than in the control group ( $\mathrm{p}=0.02)$. In Leino et al. study, a $74 \%$ increase was observed in urinary output in the dexmedetomidine group in the first $4 \mathrm{~h}$ after insertion of a urinary catheter ${ }^{18}$. The results of the present study showed no effect of intraoperative dexmedetomidine on the increase in postoperative urinary output, which may even lead to a decrease in urinary output on day 2. However, intraoperative dexmedetomidine can lead to increased urinary output. Zhai et al. showed that in comparison to the control group, the urine output during the entire process of surgery was significantly enhanced in the dexmedetomidine group ${ }^{14}$.

According to the results regarding the effect of intraoperative dexmedetomidine on inotrope intake, we found that the VasoactiveInotropic Score (VIS) score in the first, second, and third postoperative days was lower than the control group, which means lower inotrope intake in this group. But the difference was not significant in any of the days.

There was no significant difference between the Dexmedetomidine and control groups regarding the effect of intraoperative dexmedetomidine on the packed red blood cells (PRBC) usage. The results showed no effect of intraoperative dexmedetomidine on postoperative PRBC usage.

The findings of this study indicate that dexmedetomidine has no effect on the renal function of patients undergoing coronary artery bypass graft surgery that is in line with some studies and in contrast with some others. Leino et al. showed that intravenous dexmedetomidine didn't change renal function in a cohort of relatively low-risk elective CABG patients but was related to an increase in urinary output ${ }^{18}$. In shamaa et al.. study, dexmedetomidine didn't affect conventional renal functions such as serum creatinine, and creatinine clearance, and it was related to an increase in urinary output ${ }^{20}$. In Göksedef1 et al. study it was demonstrated that low-dose dexmedetomidine has no cumulative effect on urine output and renal indices including urea, creatinine, and creatinine clearance; though, it may positively affect renal functions following cardiac surgery with a total daily dosage of 110 mcg of dexmedetomidine infusions without a loading $\operatorname{dos}^{21}$. In contrast, YY et al. showed that intraoperative infusion of dexmedetomidine may decrease the occurrence of AKI ${ }^{19}$. Ji et al. revealed that post-bypass dexmedetomidine use related to a significant reduction in the occurrence of AKI, particularly mild AKI in patients with a preoperative normal renal function who undergo cardiac surgery ${ }^{22}$. Soliman et al. demonstrated that the continuous infusion of dexmedetomidine throughout cardiac surgery has a reno-protective effect and reduced the deterioration of the renal function in comparison to the continuous infusion of dopamine $^{23}$. In another study by Cho et al. perioperative infusion of dexmedetomidine efficiently decreased the occurrence and severity of AKI and improved results in patients with valvular heart surgery ${ }^{15}$. 
With regard to the studies, the effect of dexmedetomidine on renal function is controversial and it appears that the dose and timing of dexmedetomidine in improving outcomes should be considered in further trials.

\section{Conclusions}

The findings of this study indicate that dexmedetomidine does not affect the renal function of patients undergoing coronary artery bypass graft surgery. According to the findings, dexmedetomidine can increase the urine output of patients during surgery. However, it has no positive effect on the postoperative period. Also, according to the findings, dexmedetomidine does not affect the use of inotropic drugs and PRBC. Further studies are needed to definitively determine the effect of dexmedetomidine on the renal function of patients undergoing CABG. Also, evaluation of more specific renal injury indices such as IL18, SOD, NGAL will be very helpful.

\section{REFERENCE}

1. E. A. J. Hoste and W. Vandenberghe, "Epidemiology of cardiac surgeryassociated acute kidney injury", Best Pract Res Clin Anaesthesiol, 31(3), 299303 (2017).

2. R. Bellomo, S. Auriemma, A. Fabbri, A. D'Onofrio, N. Katz, P. A. McCullough, et al., "The pathophysiology of cardiac surgery-associated acute kidney injury (CSA-AKI)", Int J Artif Organs, 31(2), 166-178 (2008).

3. M. D. Okusa, "The inflammatory cascade in acute ischemic renal failure", Nephron, 90(2), 133-138 (2002).

4. J. Jalonen, M. Hynynen, A. Kuitunen, H. Heikkila, Perttila J, Salmenpera M, et al., "Dexmedetomidine as an anesthetic adjunct in coronary artery bypass grafting", Anesthesiology, 86(2), 331-345 (1997).

5. M. Vives, A. Hernandez, F. Parramon, N. Estanyol, B. Pardina, A. Munoz, et al., "Acute kidney injury after cardiac surgery: prevalence, impact and management challenges", Int J Nephrol Renovasc Dis, 12, 153-166 (2019).
6. M. Venn, J. Newman and M. Grounds, "A phase II study to evaluate the efficacy of dexmedetomidine for sedation in the medical intensive care unit", Intensive Care Med., 29(2), 201-207 (2003).

7. R. Aantaa and J. Jalonen. "Perioperative use of alpha2-adrenoceptor agonists and the cardiac patient", Eur J Anaesthesiol., 23(5), 361-372 (2006).

8. J. A. Giovannitti, J.r. S. M. Thoms and J. J. Crawford, "Alpha-2 adrenergic receptor agonists: a review of current clinical applications", Anesth Prog, 62(1), 31-39 (2015).

9. D. L. Herr, S. T. Sum-Ping and M. England, "ICU sedation after coronary artery bypass graft surgery: dexmedetomidine-based versus propofolbased sedation regimens", J Cardiothorac Vasc Anesth, 17(5), 576-584 (2003).

10. D. V. Menon, Z. Wang, P. J. Fadel, D. Arbique, D. Leonard, J. L. Li, et al., "Central sympatholysis as a novel countermeasure for cocaine-induced sympathetic activation and vasoconstriction in humans", $\boldsymbol{J}$ Am Coll Cardiol, 50(7), 626-633 (2007).

11. J. Gu, P. Sun, H. Zhao, H. R. Watts, R. D. Sanders, N. Terrando, et al., "Dexmedetomidine provides renoprotection against ischemiareperfusion injury in mice", Crit Care, 15(3), R153 (2011).

12. C. H. Hsing, C. F. Lin, E. So, D. P. Sun, T. C. Chen, C. F. Li, et al., "Alpha2Adrenoceptor agonist dexmedetomidine protects septic acute kidney injury through increasing BMP-7 and inhibiting HDAC2 and HDAC5", Am J Physiol Renal Physiol, 303(10), 1443-1453 (2011).

13. J. B. Park, S. H. Bang, H. K. Chee, J. S. Kim, S. A. Lee and J. K. Shin, "Efficacy and safety of dexmedetomidine for postoperative delirium in adult cardiac surgery on cardiopulmonary bypass", Korean J Thorac Cardiovasc Surg, 47(3), 249-254 (2014).

14. M. Zhai, F. Kang, M. Han, X. Huang and J. Li, "The effect of dexmedetomidine on 
renal function in patients undergoing cardiac valve replacement under cardiopulmonary bypass: A double-blind randomized controlled trial", J Clin Anesth, 40, 33-38 (2017).

15. J. S. Cho, J. K. Shim, S. Soh, M. K. Kim and Y. L. Kwak, "Perioperative dexmedetomidine reduces the incidence and severity of acute kidney injury following valvular heart surgery", Kidney Int, 89(3), 693-700 (2016).

16. R. Bellomo, J. A. Kellum and C. Ronco, "Acute kidney injury", Lancet, 380(9843), 756-766 (2012).

17. T. Shirasaka, H. Kannan and M. Takasaki, "Activation of a $\mathrm{G}$ proteincoupled inwardly rectifying $\mathrm{K}+$ current and suppression of Ih contribute to dexmedetomidine-induced inhibition of rat hypothalamic paraventricular nucleus neurons", Anesthesiology, 107(4), 605615 (2007).

18. K. Leino, M. Hynynen and J. Jalonen, M. Salmenpera, H. Scheinin, R. Aantaa, et al., "Renal effects of dexmedetomidine during coronary artery bypass surgery: a randomized placebo-controlled study", BMC Anesthesiol, 11, 9 (2011).

19. Y. Y. Jo, J. Y. Kim, J. Y. Lee, C. H. Choi, Y. J. Chang and H. J. Kwak, "The effect of intraoperative dexmedetomidine on acute kidney injury after pediatric congenital heart surgery: A prospective randomized trial", Medicine (Baltimore), 96(28), e7480 (2017).
20. A. S. Ammar, K. M. Mahmoud, Z. A. Kasemy and M. A. Helwa, "Cardiac and renal protective effects of dexmedetomidine in cardiac surgeries: A randomized controlled trial", Saudi $J$ Anaesth, 10(4), 395-401 (2016).

21. D. Göksedef, O. O. Balkanay, S. N. Ömeroğlu, Z. Talas, B. Arapi and Y. Junusbekov, "The effects of dexmedetomidine infusion on renal functions after coronary artery bypass graft surgery: a randomized, double-blind, placebo-controlled study", TJTCVS, 21(3), 594-602 (2013).

22. F. Ji, Z. Li, J. N. Young, A. Yeranossian and H. Liu, "Post-bypass dexmedetomidine use and postoperative acute kidney injury in patients undergoing cardiac surgery with cardiopulmonary bypass", PLoS One, 8(10), e77446 (2013).

23. R. Soliman and M. Hussien, "Comparison of the renoprotective effect of dexmedetomidine and dopamine in highrisk renal patients undergoing cardiac surgery: A double-blind randomized study", Ann Card Anaesth, 20(4), 408415 (2017). 


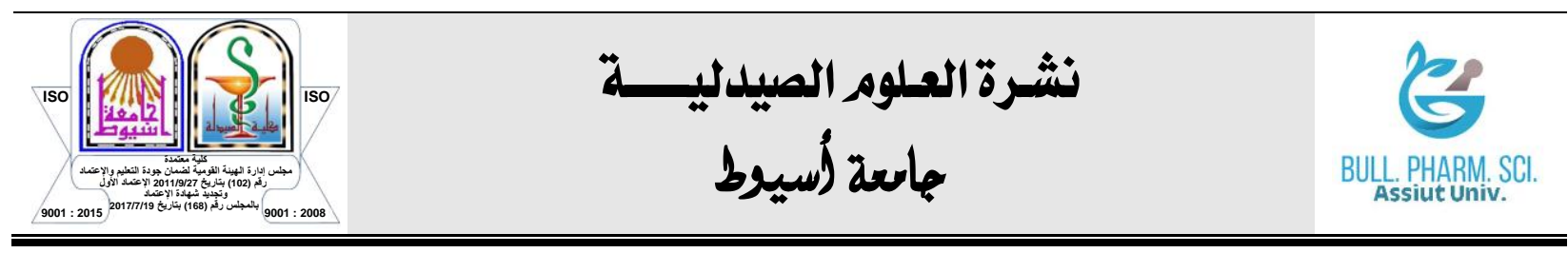

تأثير ديكسميديتوميدين أثناء العملية على وظائف الكلى في المرضى الأين

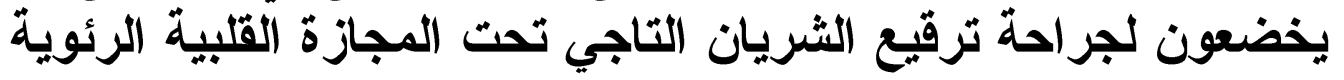

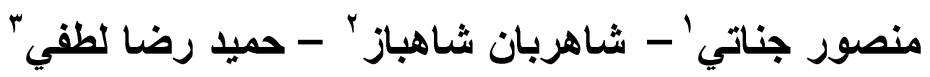

اجناح جراحة القلب والأوعية الدموية ، مستشفى نامازي ، جامعة شيراز للعلوم الطبية ، شيراز ، إيران

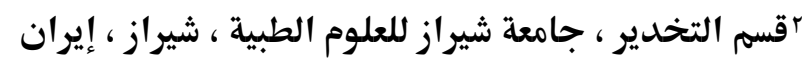

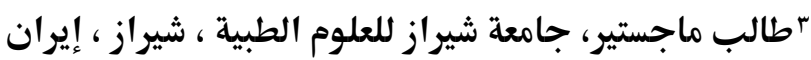

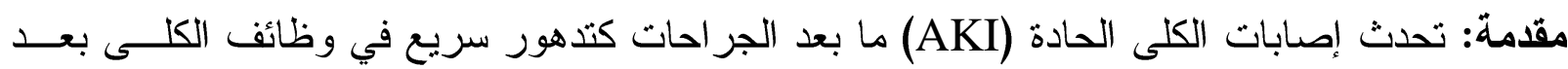

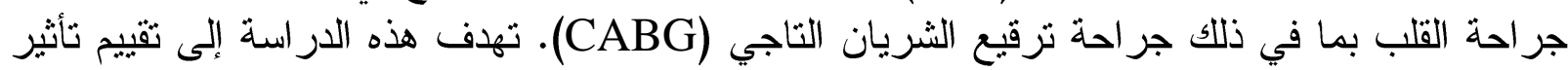

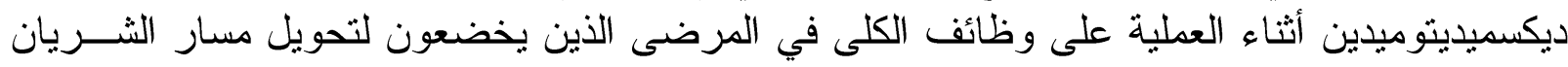
التاجي باستخدام المجازة القلبية الرئوية (CPB).

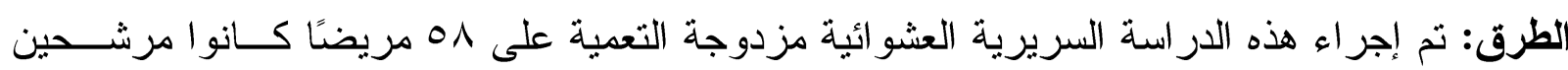

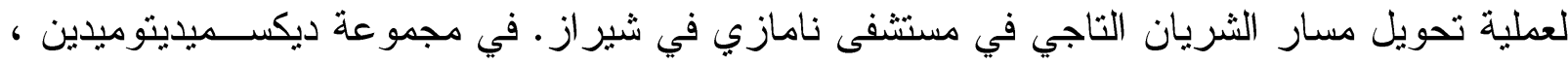

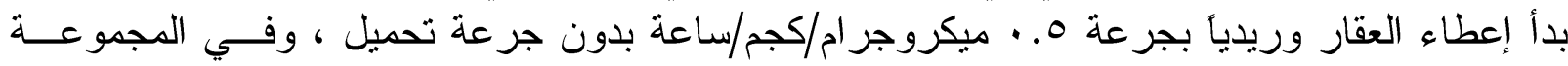

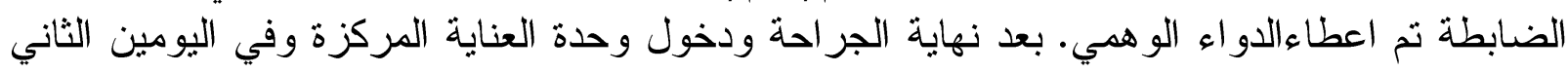

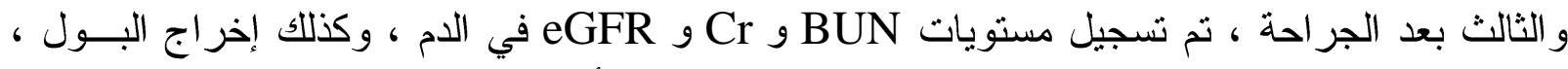

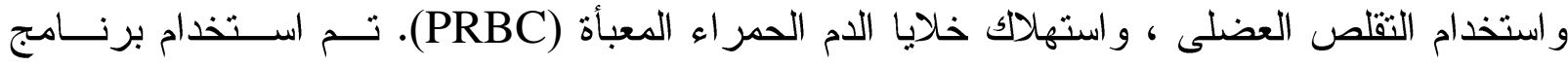
SPSS 24

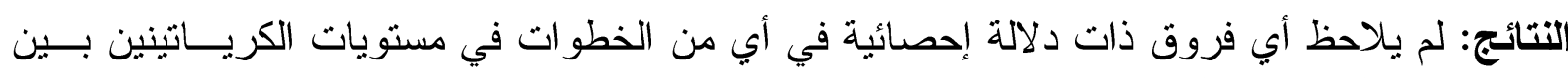

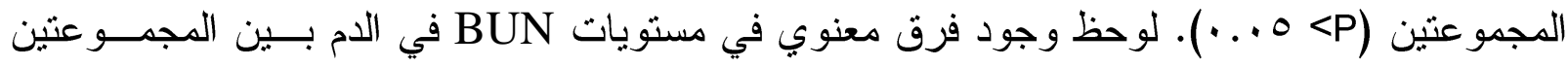

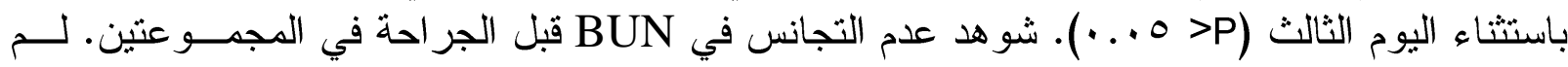

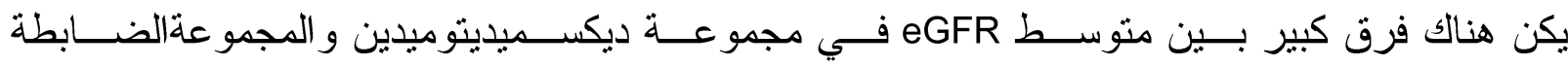

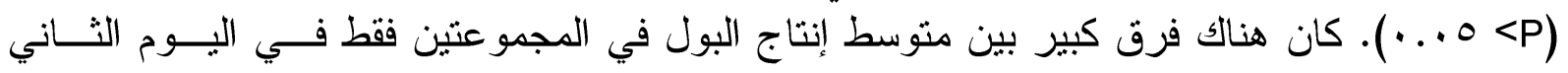
استخدام مقويات التقلص العضــلي بــين

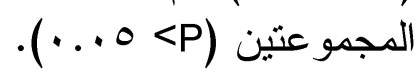

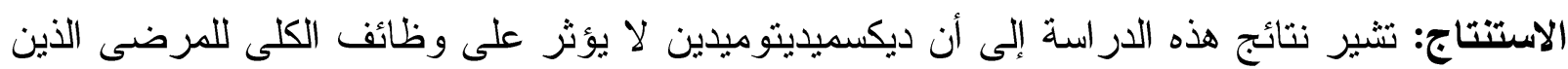

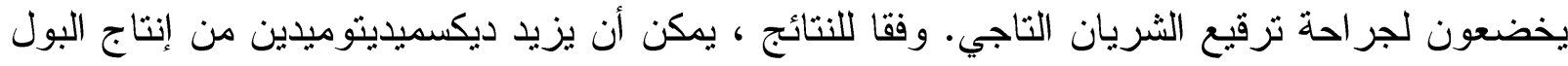

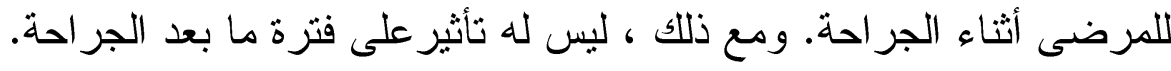

